\title{
Willingness to Pay for Childhood Malaria Vaccine Among Caregivers of Under-Five Children in Northwest Ethiopia
}

This article was published in the following Dove Press journal: ClinicoEconomics and Outcomes Research

\author{
Yohannes Wagnew' \\ Tsega Hagos ${ }^{2}$ \\ Berhanemeskel \\ Weldegerima (D) $^{3}$ \\ Ayal Debie $\mathbb{D}^{2}$ \\ 'University of Gondar Comprehensive \\ and Specialized Referral Hospital, \\ University of Gondar, Gondar, Ethiopia; \\ ${ }^{2}$ Department of Health Systems and \\ Policy, Institute of Public Health, College \\ of Medicine and Health Sciences, \\ University of Gondar, Gondar, Ethiopia; \\ ${ }^{3}$ Department of Pharmaceutics, School of \\ Pharmacy, College of Medical and Health \\ Sciences, University of Gondar, Gondar, \\ Ethiopia
}

Background: Malaria, a protozoan disease caused by the genus Plasmodium, is responsible for serious illnesses and death across the world. RTS, S/AS01 (Mosquirix ${ }^{\mathrm{TM}}$ ) is a recombinant protein-based malaria vaccine valuable for the prevention and control of the disease. However, studies done so far on the willingness to pay (WTP) malaria vaccine have been inadequate to inform policy-makers.

Methods: A community-based cross-sectional study was conducted to assess the WTP for childhood malaria vaccine and associated factors among caregivers of under-five children from February to April 2019 in West Dembia district. A multistage stratified systematic sampling technique was used, and the contingent valuation method was used to estimate caregivers' willingness to pay for the vaccine. AOR with $95 \% \mathrm{CI}$ and less than $0.05 \mathrm{p}$-values were used to declare factors associated with WTP.

Results: Overall, $60.6 \%$ (95\% CI: $56.60,64.40 \%$ ) of caregivers of under-five children were WTP for the childhood malaria vaccine at a price of US\$ 23.11 per full doses. Urban residence $(\mathrm{AOR}=1.78,95 \% \mathrm{CI}: 1.04,3.04)$, educational status $(\mathrm{AOR}=3.27 ; 95 \% \mathrm{CI}: 1.07$, 9.94) and vaccination experience for children $(\mathrm{AOR}=2.12 ; 95 \% \mathrm{CI}: 1.29,3.48)$ were positively associated with the WTP. WTP for the vaccine was higher among rich households $(\mathrm{AOR}=3.15 ; 95 \% \mathrm{CI}: 1.90,5.22)$, caregivers who had the previous history of malaria attack $(\mathrm{AOR}=2.62 ; 95 \% \mathrm{CI}: 1.68,4.08)$, households with fewer members $(\mathrm{AOR}=1.59 ; 95 \% \mathrm{CI}$ : $1.06,2.40)$, and families more knowledgeable about malaria prevention and control $(\mathrm{AOR}=3.56$; 95\% CI: $1.83,6.93)$ compared with their counterparts.

Conclusion: The majority of the participants were WTP for the childhood malaria vaccine. A significant rise in willingness to purchase was observed at price below the profile price. Thus, it is of great value to policy-makers to understand the price sensitivity before setting the price of the vaccine.

Keywords: willingness to pay, malaria vaccine, under-five children, northwest, Ethiopia

\section{Background}

Malaria, a protozoan disease caused by the genus Plasmodium, is responsible for serious illness and death across the world. ${ }^{1}$ In developing countries, it is one of the leading causes of morbidity and mortality, particularly affecting children and pregnant women. ${ }^{2}$ Every year, malaria claims the lives of more than 400,000 people. ${ }^{3}$ The WHO African region accounting 93\% of the global malaria deaths and $61 \%$ of them were under-five children. ${ }^{4}$ Moreover, about $71 \%$ and $86 \%$ of the global cases and deaths were contributed by Sub-Saharan African countries,
Correspondence: Ayal Debie University of Gondar, P.O. Box: 196,

Gondar, Ethiopia

Email debieayal@gmail.com 
respectively. ${ }^{2}$ In Ethiopia, about $68 \%$ of the population (52 million) is at risk for contracting malaria, and Plasmodium falciparum and vivax are the main species, accounting for $60 \%$ and $40 \%$ of cases, respectively. ${ }^{5}$

WHO recommends that Indoor Residual Spraying (IRS), Insecticide-Treated Nets (ITNs), larval control, preventative chemotherapy, early diagnosis and treatment to prevent and control the disease. ${ }^{3,4}$ The malaria vaccine is under evaluation in Ghana, Kenya, and Malawi for use as a complementary control tool. ${ }^{3}$ RTS, S/AS01 (RTS, S) (Mosquirix $^{\mathrm{TM}}$ ) is the world's first licensed and proteinbased recombinant malaria vaccine that protects against Plasmodium falciparum. ${ }^{6,7}$

Between 2009 and 2014, RTS, S underwent a rigorous testing among children aged 5-17 months through a largescale Phase 3 trial, and the finding showed the vaccine prevented 4 in 10 cases of malaria (39\%) and 3 in 10 $(29 \%)$ cases of severe malaria. ${ }^{3}$

Malaria transmission has unstable seasonal variations that coincide with the major planting and harvesting seasons of communities. Thus, it is one of the major causes of economic loss and low gross domestic product growth due to loss of personnel productivity and school absenteeism in Ethiopia. ${ }^{5,8}$ Increasing parasite resistance to anti-malarial drugs, poor income, low LLINs utilization, poor IRS compliances, inadequate access and unfair distribution of health care and insufficient health service infrastructures and high population movements were affecting the effectiveness of malaria prevention and control in the country. ${ }^{9}$

The provision of four doses of the RTS,S/AS01 vaccine complimented with other preventive and control packages to children above 5 months of age, given at 6 , 7.5, 9 and 18 months after the third dose, ${ }^{10}$ had a significant impact on the reduction of malaria morbidity and mortality. ${ }^{11}$

The vaccine is given at 6, 7, 9, and 24 months of the age of children. ${ }^{12}$ The first and the third doses of the vaccine align with the 6-month vitamin A supplementation and the 9-month first dose of the measles vaccine, respectively, and the fourth dose is given after 15-18 months of the third dose. This new vaccine would require two additional immunization contacts to align with the current EPI program of Ethiopia.

The full course (four doses) of the vaccine cost per a child was US\$23.11-28.28. ${ }^{10}$ In developing countries including Ethiopia, the payment mechanism for the healthcare cost is Out-Of-Pocket (OOP) mainly paid at the time of sickness or point of service delivery which could inhibit healthcare access and lead to impoverishment. ${ }^{13}$

To curb this problem, the Government of Ethiopia began to implement a Community Based Health Insurance (CBHI) in 2010/11. ${ }^{14}$ The insurance, one of the most developed forms of health micro-insurance, is a

... non-profit health insurance scheme for the informal sector, formed on the basis of an ethic of mutual aid and the collective pooling of health risks, in which members participate in its management. ${ }^{15}$

In Ethiopia, the premium for CBHI has been the same (US $\$ 8.27$ per annum) to all households, regardless of economic status. ${ }^{14}$ As such a flat premium is inequitable, the government is working to introduce a stratified premium based on household willingness and ability to pay.

However, studies that have been done so far on the assessment of WTP for childhood malaria vaccine are not adequate to inform policy-makers. Therefore, this study aimed to assess the WTP for childhood malaria vaccine and associated factors among caregivers of under-five children in West Dembia district, northwest Ethiopia.

\section{Methods and Materials Study Design}

A community-based cross-sectional study was conducted to assess the WTP for childhood malaria vaccine and associated factors among caregivers of under-five children in West Dembia district, northwest Ethiopia. The design of the study is believed to enable to determine the prevailing characteristics of the population at a certain point in time. The data were collected using a semi-structured questionnaire, and unique house numbers were given to each house in the selected kebeles. The data were collected through face-to-face interviews near the gateway of each caregiver's house. The interviewing process took approximately 25-30 minutes per participant.

\section{Study Settings and Period}

The study was conducted in the Amhara National Regional State, the second largest region in the country, located in the northwest and north-central part. This study was conducted in West Dembia district, northwest Ethiopia, from February to April 2019. The district located $228 \mathrm{~km}$ from Bahir Dar (Capital of the Regional State), has 3 urban and 20 rural kebeles (the smallest administrative unit in Ethiopia). According to the 2018 report of the district health office, 133,768 people and an estimated 39,408 
under-five children lived in West Dembia, served by 5 health centers, 20 health posts and 10 private clinics (Figure 1).

\section{Population and Sampling Procedure}

All caregivers of the under-five children in the district were the source population and those who had chances to participate in selection in the selected kebeles were the study population. All permanent resident caregivers of under-five children in selected households during data collection were eligible to participate. However, caregivers who were seriously ill and physically incapable were excluded. The sample size was calculated using the single population proportion formula assuming $50 \%$ proportion(p) of caregivers, $95 \%$ confidence level, $5 \%$ margin of error, 1.5 design effect and $10 \%$ non-response rate that yielded 634 participants as the final sample. Then, the district was stratified into urban and rural kebeles. Finally, one urban and four rural kebeles, namely Chuahit, Meserete Kristos, Abrija, Narchecha and Sankissa were selected using the lottery method. Lists of households in the selected kebeles were obtained from the health posts of the selected kebeles in the district. Thus, the sample was proportionally allocated to each kebele

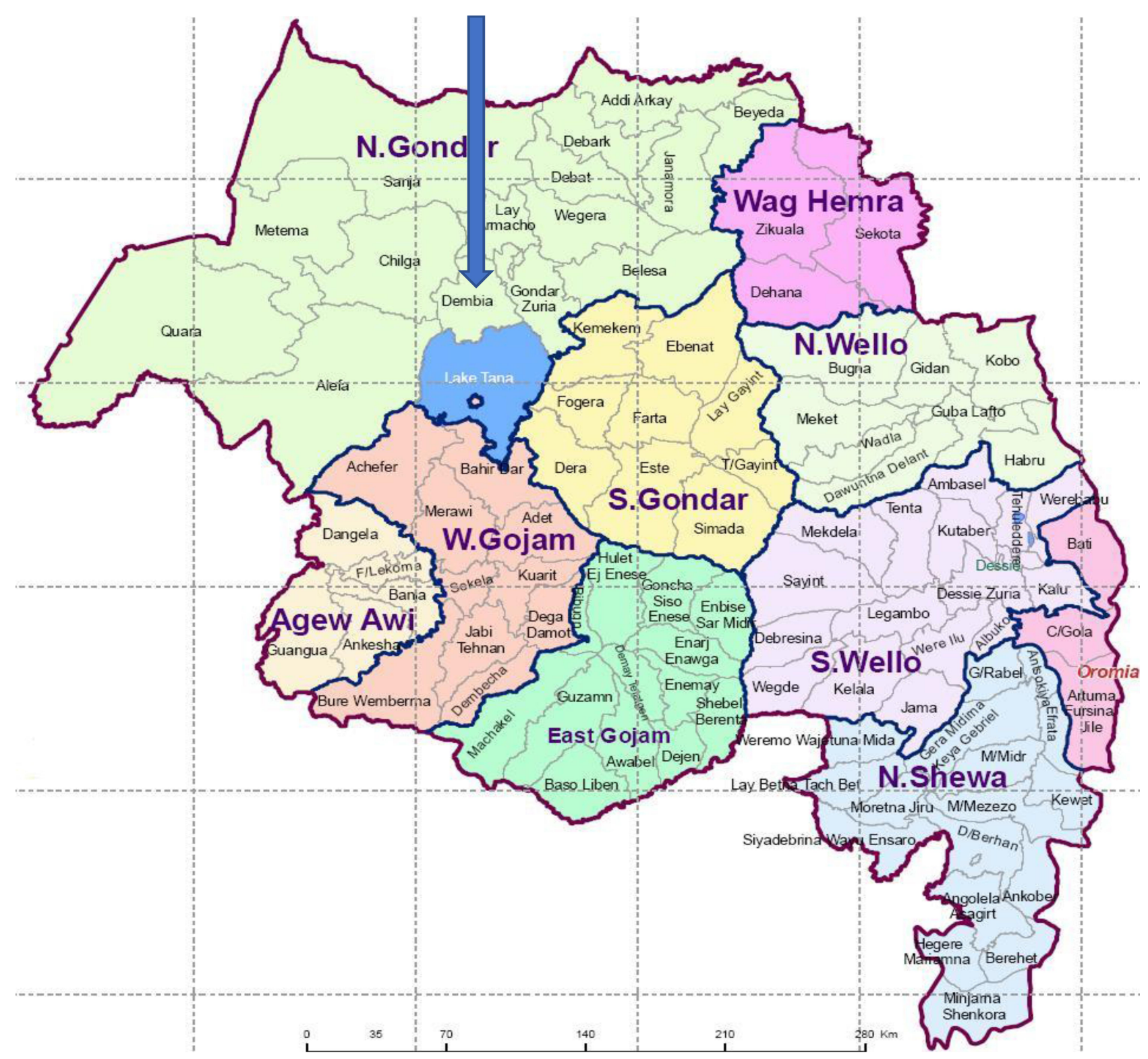

Figure I Map of Dembia district in North Gondar zone districts in Amhara National Regional State, northwest Ethiopia, 2005. Note: Ethiopian demographic and health survey/EDHS (2005). 
based on their number of households. The total households in the selected kebeles (4394) (West Dembia district health office, Woreda health office annual action planning, 2018), were divided by the sample, 634 to determine the sampling interval, seven. The first household was selected out of the first seven, using the lottery method, and every seventh household was selected using the systematic sampling technique.

\section{Data Collection Procedures and Measurements}

Data were collected using an interviewer administered structured questionnaire through reviewing the literature. $^{16-19}$ The questionnaire was first prepared in English translated to Amharic and back to English to check the consistency.

Knowledge of participants was also measured using eight-item malaria prevention and control-related questions. Each item contained " 0 " for "no" and " 1 " for "yes" alternatives and participants who scored " $<50$ ", " $50-75$ " and " $>75 \%$ " were considered as having "poor", "moderate" and "good" knowledge, respectively. ${ }^{20}$ Wealth status was also determined by using the principal component analysis and ranked into 3 quintiles as poor, medium

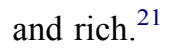

Willingness to accept malaria vaccine was measured by asking the respondents: "Are you willing to pay for malaria vaccine?" The alternative options were: "Yes" or "No". WTP was defined as the maximum amount of money individuals were willing to pay for the vaccine measured by the bid contingent valuation method. It is the proportion of caregivers who were willing to purchase a full dose of the vaccine for their under-five children. ${ }^{22}$ Those caregivers who are willing to pay ETB 648 (US\$ 23.11) per child/full doses were considered as WTP the malaria vaccine.

The double-bound dichotomous choice variant of the contingent valuation method was used to estimate participants' maximum/minimum willingness to purchase the vaccine. $^{20}$ Caregivers' WTP for the vaccines was measured after describing the hypothetical scenario about the substance as follows:

Malaria vaccine has the potential to help get malaria control back on track, and may prove to be important in relation to the current control tools. This malaria vaccine will be given to your child with 3 initial doses at 6,7 , and 9 months, and the fourth dose will be administered after 15 months of the third dose. The vaccine can prevent your child from getting Plasmodium falciparum malaria approximately 4 in 10 cases and 3 in 10 severe malaria cases, but has not yet been proven against vivax. Similarly, your child is protected from getting malaria for an average duration of four years after receiving the full course of the vaccine. The vaccine given by injection has an acceptable safety and tolerability profile for the child. As a result, it may result in some local pain, swelling, and low-grade fever, reactions similar to other vaccines given to children.

The profile price was US\$ 5.78/dose (US\$ 23.11/full doses). ${ }^{10}$ The caregivers were first asked whether they would be willing to pay for the vaccine or not. If they were willing to pay for the vaccine; then, they were asked "Are you willing to pay ETB 648 (US\$23.11) per child/full doses of the vaccine?". Subsequently, the data collectors continued to elicit a lower or higher bid value depending on the demand of the respondents to determine the caregiver's maximum/ minimum WTP using the iterative bidding technique (Figure 2). As a result, caregivers who were willing and able to pay ETB 648 (US\$ 23.11 or above) per child per full doses were considered as willing to pay for the malaria vaccine.

\section{Data Quality Control}

Four BSc graduate clinical nurses and two such public health professionals were recruited as data collectors and supervisors, respectively. A one-day training was given to both groups on the basic techniques of data collection procedures. Pre-test was administered on 32 under-five caregivers in Takusa district 2 weeks before the actual data collection. Moreover, reinterviews on 15 participants were conducted in person to validate the consistency of responses between the interview and reinterview and it was consistent. The completeness and consistency of the collected data were daily checked on the spot by the supervisors and the principal investigator.

\section{Data Management and Analysis}

Data were entered into Epi-Data version 3.1 and exported to STATA software version 14 for analyses. Descriptive statistics such as percentages, frequencies, means and medians were used to describe the study population in relation to the relevant variables. The binary logistic regression model was used to determine factors associated with the WTP for childhood malaria vaccines. Variables with less than $0.2 \mathrm{p}$-values were fitted into the multivariable logistic regression analysis. The Adjusted Odds Ratio (AOR) with a $95 \% \mathrm{CI}$ and less than 0.05 p-values were 


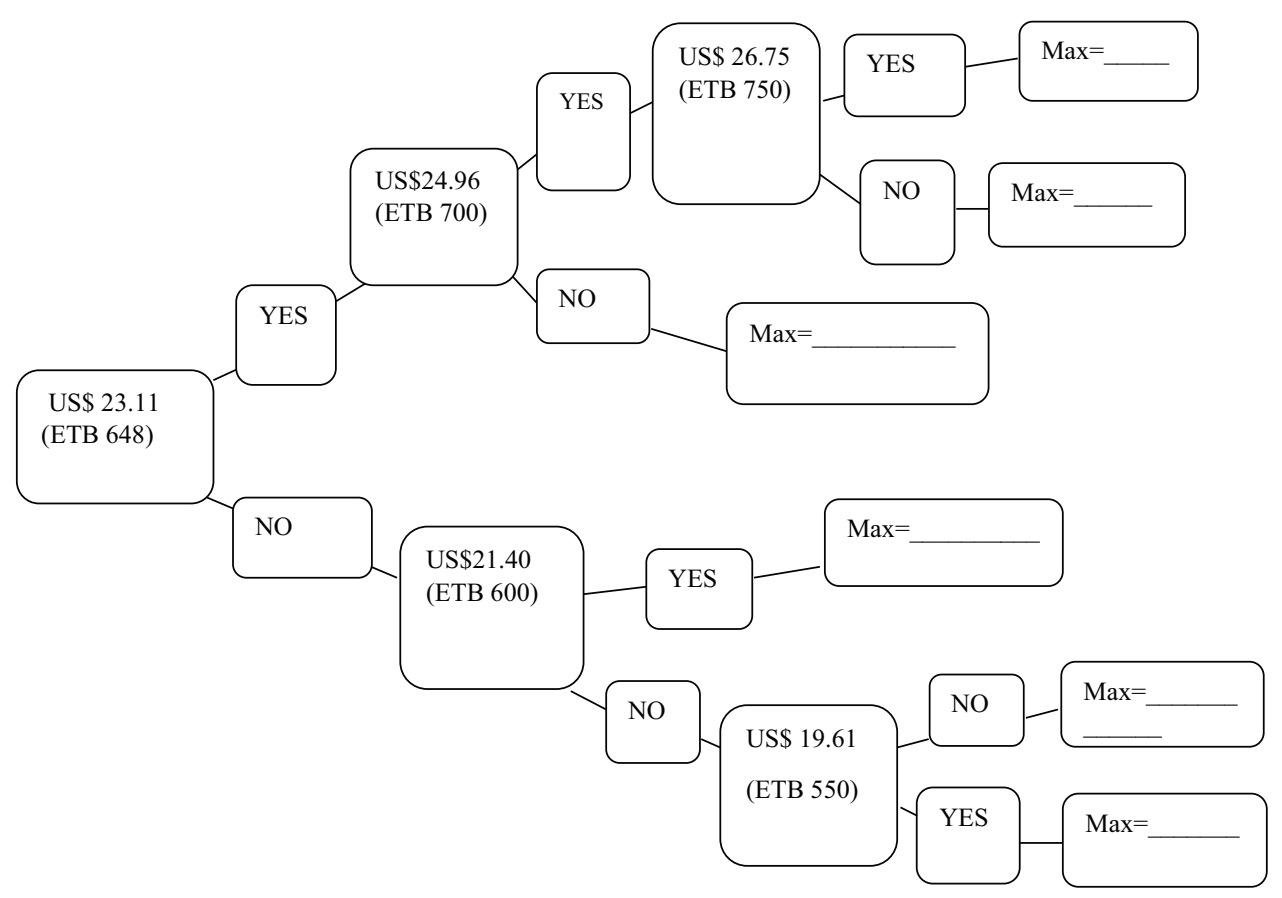

Figure 2 Iterative bidding technique to elicit WTP for malaria vaccine among participants in West Dembia district, 2019.

used to declare variables significantly associated with WTP for childhood malaria vaccines.

\section{Ethics Approval and Consent to Participate}

This study was conducted in accordance with the Declaration of Helsinki. Ethical clearance was obtained from the Ethical Review Committee of the Institute of Public Health, College of Medicine and Health Sciences, University of Gondar on 05 February 2019 with a reference number IPH/180/06/2019. Permission was also obtained from Central Gondar zone health department and West Dembia district health office. Written informed consent was obtained from the study participants after explaining the purpose of the study and confidentiality of the information was ensured by coding. Participants were given the full right to skip any question and terminate their participation at any stage.

\section{Results}

\section{Socio-Demographic and Economic Characteristics}

A total of 604 caregivers of under-five children participated in the study with a response rate of $95.3 \%$. The mean age of the respondents was 32.6 ( $\pm 7.3 \mathrm{SD})$ years; half of the caregivers aged 21-34 years were unable to read and write. More than $85 \%$ of the respondents were female, Orthodox Christian, and married. Above threefourths $(76.6 \%)$ were dwellers in rural areas and $56.5 \%$ were housewives. Moreover, the average number of household members was 5.2, and one-third (34\%) of the participants were classified as poor by wealth status (Table 1).

\section{Health Service Utilization and Knowledge of Participants}

Over $80 \%$ of the participants had previous experience of vaccinating their children. More than $40 \%$ of caregivers had a history of malaria attack. Around $20 \%$ of the children had a history of malaria attack in the past 1 year. Furthermore, $12 \%$ of the respondents were fee waiver users (the poorest segment exempted from payment for health care services); $43 \%$ were members of the Community-Based Health Insurance (CBHI). Thirty percent of the participants had poor knowledge about the disease symptoms, risk factors, and the prevention and control of malaria; $8.8 \%$ heard about malaria vaccine (Table 2).

\section{Willingness to Pay Malaria Vaccine}

Over $90 \%$ of the caregivers were willing to accept and over $60 \%$ were willing to purchase the vaccine at US\$ 23.11 per full doses per child. The mean price that caregivers were willing to purchase the full doses per child was ETB 724 (US 
Table I Socio-Demographic and Economic Characteristics of the Caregivers of Under-Five Children at West Dembia District, Northwest Ethiopia, $2019(n=604)$

\begin{tabular}{|c|c|c|c|}
\hline Variables & Category & Frequency & Percent (\%) \\
\hline \multirow[t]{2}{*}{ Resident } & Rural & 463 & 76.66 \\
\hline & Urban & 141 & 23.34 \\
\hline \multirow[t]{2}{*}{ Sex } & Female & 518 & 85.76 \\
\hline & Male & 86 & 14.24 \\
\hline \multirow[t]{3}{*}{ Age in years } & $18-30$ & 265 & 43.87 \\
\hline & $31-45$ & 312 & 51.66 \\
\hline & $\geq 46$ & 27 & 4.47 \\
\hline \multirow[t]{3}{*}{ Religion } & Orthodox & 521 & 86.26 \\
\hline & Muslim & 81 & $|3.4|$ \\
\hline & Others & 2 & 0.33 \\
\hline \multirow[t]{4}{*}{ Marital status } & Single & 35 & 5.79 \\
\hline & Married & 545 & 90.23 \\
\hline & Widowed & 18 & 2.98 \\
\hline & Divorced & 6 & 0.99 \\
\hline \multirow[t]{5}{*}{ Education } & Unable to read and write & 306 & 50.66 \\
\hline & Able to read and write & 140 & 23.18 \\
\hline & Primary school & 59 & 9.77 \\
\hline & Secondary school & 69 & 11.42 \\
\hline & Higher education & 30 & 4.97 \\
\hline \multirow[t]{5}{*}{ Occupation } & Farmer & 137 & 22.68 \\
\hline & Employee & 30 & 4.97 \\
\hline & Merchant & 76 & 12.58 \\
\hline & Daily Labor & 20 & 3.31 \\
\hline & House wife & 341 & 56.46 \\
\hline \multirow[t]{2}{*}{ Family size } & $<5$ & 336 & 55.63 \\
\hline & $\geq 5$ & 268 & 44.37 \\
\hline No of $<5$ & One & 509 & 84.27 \\
\hline children & $\geq$ Two & 95 & 15.73 \\
\hline \multirow[t]{3}{*}{ Wealth status } & Rich & 201 & 33.44 \\
\hline & Medium & 197 & 32.62 \\
\hline & Poor & 206 & 34.11 \\
\hline
\end{tabular}

\$25.82) or ETB 181 (US\$6.46) per single dose. As a result, the study showed that there was a significant increase in willingness to purchase when the price was below the profile (US\$ 23.11) or vice versa (Figure 3).
Table 2 Health Status and Knowledge of Participants at West Dembia District, Northwest Ethiopia, $2019(n=604)$

\begin{tabular}{|c|c|c|c|}
\hline Variables & Category & Frequency & Percent (\%) \\
\hline \multirow{2}{*}{$\begin{array}{l}\text { Experience about } \\
\text { childhood vaccination }\end{array}$} & Yes & 504 & 83.44 \\
\hline & No & 100 & 16.56 \\
\hline \multirow{2}{*}{$\begin{array}{l}\text { Caregivers attacked by } \\
\text { malaria in the last year }\end{array}$} & Yes & 268 & 44.37 \\
\hline & No & 336 & 55.63 \\
\hline \multirow{3}{*}{$\begin{array}{l}\text { Malaria episodes } \\
\text { per year }\end{array}$} & 0 & 336 & 55.63 \\
\hline & 1 & 184 & 30.46 \\
\hline & $\geq 2$ & 84 & $13.9 \mid$ \\
\hline \multirow{2}{*}{$\begin{array}{l}\text { Children attacked by } \\
\text { malaria in the past } \\
\text { one year }\end{array}$} & Yes & 118 & 19.54 \\
\hline & No & 486 & 80.46 \\
\hline \multirow[t]{2}{*}{ Fee-waiver users } & Yes & 71 & 11.75 \\
\hline & No & 533 & 88.25 \\
\hline \multirow[t]{2}{*}{$\mathrm{CBHI}$ members } & Yes & 259 & 42.88 \\
\hline & No & 345 & 57.12 \\
\hline \multirow{2}{*}{$\begin{array}{l}\text { Heard about malaria } \\
\text { vaccine }\end{array}$} & Yes & 53 & 8.77 \\
\hline & No & 551 & 91.23 \\
\hline \multirow[t]{3}{*}{ Knowledge } & Good & 178 & 29.47 \\
\hline & Moderate & 352 & 58.28 \\
\hline & Poor & 74 & 12.25 \\
\hline
\end{tabular}

\section{Reasons for Not Willing to Pay}

Unwilling to accept, lack of readiness to pay and inability to afford the cost accounted for $13 \%, 24.4 \%$ and $62.6 \%$ of the caregiver's poor demand for the vaccine, respectively. Besides, the absence of promotions on media, uncooperative partners and fear of injections were among the common reasons for $4.2 \%, 1.3 \%$ and $7.6 \%$ of the lack of acceptance of the vaccine, respectively.

\section{Factors Associated with WTP for Malaria Vaccine \\ The odds of WTP for the vaccine were 1.78 times} $(\mathrm{AOR}=1.78,95 \% \mathrm{CI}: 1.04,3.04)$ higher among urban residents compared to rural dwellers. Similarly, the odds of purchasing the vaccine were 3.27 times $(\mathrm{AOR}=3.27$; $95 \%$ CI: $1.07,9.94)$ higher among caregivers who had higher education compared to those unable to read and write participants. The odds of willingness and ability to 


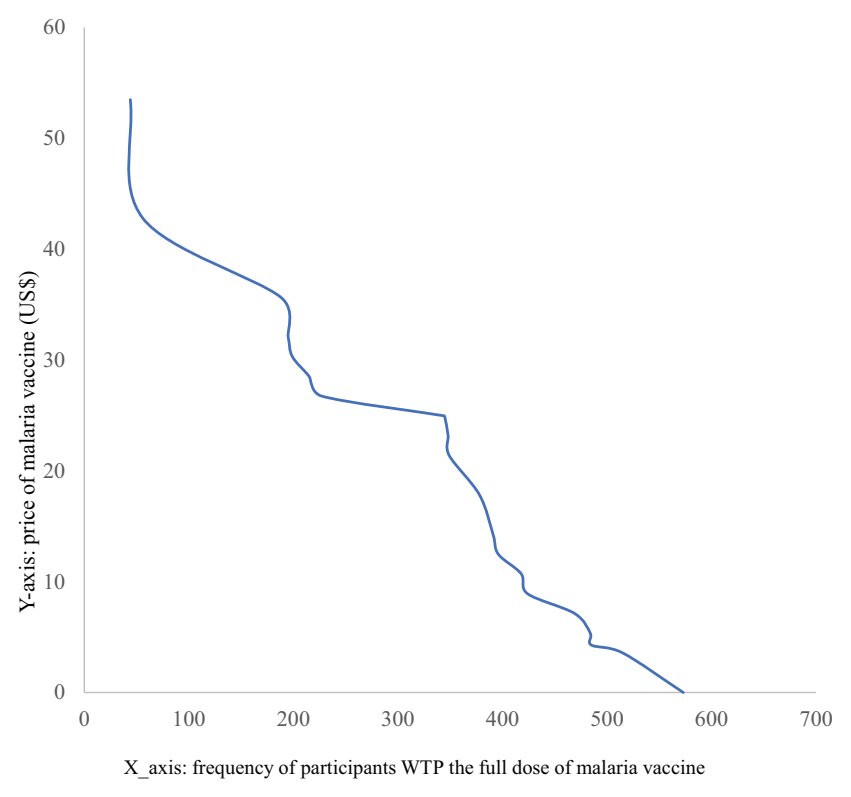

Figure 3 Participants' maximum WTP for malaria vaccine across different prices in West Dembia district, 2019.

buy the vaccine were 2.12 times $(\mathrm{AOR}=2.12 ; 95 \% \mathrm{CI}$ : $1.29,3.48)$, and 2.62 times $(\mathrm{AOR}=2.62 ; 95 \% \mathrm{CI}: 1.68$, 4.08) more among respondents with vaccination experience of their children and history of malaria attack compared to their counterparts, respectively. Furthermore, the odds of demand for the vaccine were 1.59 times $(\mathrm{AOR}=1.59 ; 95 \% \mathrm{CI}: 1.06,2.40)$, and 3.56 times $(\mathrm{AOR}=3.56 ; 95 \% \mathrm{CI}: 1.83,6.93)$ more among households who had fewer household members and good knowledge about malaria prevention and control compared to their corresponding counterparts. Besides, the odds of WTP for the vaccine were 3.15 times $(\mathrm{AOR}=3.15 ; 95 \% \mathrm{CI}: 1.90$, 5.22 ) higher among rich caregivers compared to poor ones (Table 3).

\section{Discussion}

The candidate malaria vaccine (RTS, S) is available in an injectable form and will prevent approximately 39\% of the malaria and $29 \%$ of the severe malaria cases. ${ }^{3}$ Thus, this study aimed to assess the demand for the malaria vaccine and factors associated with caregivers of under-five children in West Dembia district.

WTP for childhood malaria vaccine among caregivers of under-five children was $60.6 \%$ (95\% CI: 56.60, 64.40) at a price of US\$23.11 per full dose. This finding was lower than studies done in South Eastern Nigeria $(96.2 \%),{ }^{23}$ Ibadan, Nigeria $(87 \%),{ }^{16}$ Kenya $(88 \%),{ }^{24}$ WTP for each hypothetical malaria vaccine types A,
$\mathrm{B}$ and $\mathrm{C}$ in Nigeria. These three hypothetical vaccines had different characteristics. That is, vaccine A was $75 \%$ effective, protected for 3 years and well tolerated; vaccine $\mathrm{B}$ was $85 \%$ effective, protected for 6 years, and less well tolerated than vaccine $\mathrm{A}$; vaccine $\mathrm{C}$ was $95 \%$ effective and protected for 12 years, but the least well tolerated, ${ }^{18}$ however, it was lower than a study conducted in South Eastern Nigeria $(40.6 \%){ }^{23}$ The possible justification for these discrepancies could be the difference in study settings, periods and socio-demographic chrematistics of participants. The high WTP for malaria vaccine might also be due to the high burden of childhood malaria morbidity and mortality in the study area as it is the most malaria in Ethiopia.

The mean price of the vaccine for caregivers willing to purchase the full doses per child was ETB 724 (US\$25.82) or ETB 181 (US\$6.46) per dose per child. The mean price that respondents were willing to pay for a single dose of the vaccine was higher than the prices set in studies done in Burkina Faso (US\$ 1.91) ${ }^{17}$ and the hypothetical vaccine type C Nigeria (US\$ 5.06). ${ }^{18}$ The possible explanation for this variation could be differences in study settings, study populations and periods.

The mean price for WTP for malaria vaccine in this particular study was lower than those of studies done in Tigray region, Ethiopia (US\$ 8.37) per person per year ${ }^{20}$ and for the Nigerian hypothetical A type (US\$6.77) per dose. ${ }^{19}$ This variation might be due to the current inflation of the local currency in relation to time.

In this study, urban caregivers of under-five children were more likely to be willing to purchase the vaccine compared to rural residents. This finding is supported by a study in Burkina Faso. ${ }^{17}$ The possible justification might be the better accessibility of health infrastructures and health information to users in urban areas.

Participants who had secondary and above education were positively associated with the demand for the vaccine. This finding is consistent with the results of studies done in Ethiopia, ${ }^{20,25}$ Nigeria, ${ }^{16}$ and Vietnam. ${ }^{22}$ The possible explanation might be that educated respondents have better awareness and a favorable attitude towards health services than uneducated ones. In addition, it could be due to the fact that educated people tend to have an interest in improving family health and are readier for new interventions.

The odds of willingness and ability to buy the vaccine were higher among respondents who had vaccination experience of their child compared to caregivers who had no such experience. The finding was consistent with those of studies done in Nigeria ${ }^{16}$ and Vietnam. ${ }^{22}$ The possible 
Table 3 Factors Associated with WTP for Malaria Vaccine Among Caregivers of Under-Five Children in West Dembia District, Northwest Ethiopia, 2019

\begin{tabular}{|c|c|c|c|c|}
\hline \multirow[t]{2}{*}{ Variables } & \multicolumn{2}{|c|}{ Demand for MV } & \multirow{2}{*}{ COR $(95 \% \mathrm{Cl})$} & \multirow[t]{2}{*}{ AOR $(95 \% \mathrm{Cl})$} \\
\hline & Yes & No & & \\
\hline \multicolumn{5}{|l|}{ Resident } \\
\hline Rural & 261 & 202 & I & 1 \\
\hline Urban & 105 & 36 & $2.26(I .48,3.44)$ & $1.78(1.04,3.04) *$ \\
\hline \multicolumn{5}{|l|}{ Educational status } \\
\hline Unable to read and write & 158 & 148 & 1 & 1 \\
\hline Able to read and write & 91 & 49 & $1.74(1.15,2.63)$ & $1.84(1.12,3.01) *$ \\
\hline Primary school & 36 & 23 & $1.47(0.83,2.59)$ & $1.05(0.54,2.04)$ \\
\hline Secondary school & 56 & 13 & $4.04(2.12,7.68)$ & $2.4(1.06,5.19) *$ \\
\hline Higher education & 25 & 5 & $4.68(1.75,12.55)$ & $3.27(1.07,9.94) *$ \\
\hline \multicolumn{5}{|l|}{ Number of $<5$ children } \\
\hline 1 & 316 & 193 & I.47(0.95,2.27) & $1.30(0.78,2.18)$ \\
\hline$\geq 2$ & 50 & 45 & I & I \\
\hline \multicolumn{5}{|c|}{ Experience about childhood vaccination } \\
\hline Yes & 324 & 180 & $2.48(1.61,3.85)$ & $2.12(1.29,3.48) *$ \\
\hline No & 42 & 58 & I & I \\
\hline \multicolumn{5}{|c|}{ Caregivers attacked by malaria in last I year } \\
\hline Yes & 201 & 67 & $3.11(2.19,4.38)$ & $2.62(1.68,4.08) *$ \\
\hline No & 165 & 171 & I & I \\
\hline \multicolumn{5}{|c|}{ Children attacked by malaria in last I year } \\
\hline Yes & 92 & 26 & $2.74(1.71,4.38)$ & $1.73(0.95,3.16)$ \\
\hline No & 274 & 212 & I & I \\
\hline \multicolumn{5}{|l|}{ Fee-waiver users } \\
\hline Yes & 23 & 48 & $0.27(0.16,0.45)$ & $0.59(0.31,1.14)$ \\
\hline No & 343 & 190 & I & 1 \\
\hline \multicolumn{5}{|l|}{ Member of $\mathrm{CBHI}$} \\
\hline Yes & 170 & 89 & $1.45(1.04,2.02)$ & I.I4(0.76,I.69) \\
\hline No & 196 & 149 & I & I \\
\hline \multicolumn{5}{|l|}{ Family size } \\
\hline$<5$ & 221 & 115 & $1.63(1.17,2.26)$ & $1.59(1.06,2.40) *$ \\
\hline$\geq 5$ & 145 & 123 & I & I \\
\hline \multicolumn{5}{|l|}{ Knowledge of caregivers } \\
\hline Good & $13 \mid$ & 47 & $5.8(3.22,10.47)$ & $3.56(1.83,6.93) *$ \\
\hline Moderate & 211 & $14 \mid$ & $3.12(1.83,5.3)$ & $2.39(1.31,4.34) *$ \\
\hline Poor & 24 & 50 & I & I \\
\hline \multicolumn{5}{|l|}{ Wealth status } \\
\hline Rich & 147 & 54 & $3.0(1.98,4.54)$ & $3.15(1.90,5.22) *$ \\
\hline Medium & 121 & 76 & $1.75(1.18,2.61)$ & $1.80(1.12,2.91) *$ \\
\hline Poor & 98 & 108 & I & 1 \\
\hline
\end{tabular}

Note: *Significant at $\mathrm{p}$-value $<0.05$.

Abbreviation: MV, malaria vaccine.

reasons might be that experienced respondents might have adequate information about the importance of the vaccine to prevent the disease.
Caregivers who had fewer household members were also willing to pay for the malaria vaccine than caregivers who had more household members. This finding is 
consistent with the results of studies conducted in Nigeria, ${ }^{16}$ Thailand, ${ }^{26}$ and Burkina Faso. ${ }^{17}$ The possible explanation might be that participants who had larger household members needed more resources to fulfill the basic needs of the families, such as food, shelter and education.

Participants who were attacked by malaria were more likely to purchase the vaccine compared to their counterparts. This finding is supported by studies conducted in Tigray ${ }^{19}$ and Nigeria. ${ }^{18}$ The possible justification might be that those who were attacked understood the pain relating to the disease and its complications.

Furthermore, caregivers of under-five children who had good knowledge about malaria were more likely to be willing to purchase the vaccine than participants who had poor knowledge. This finding is consistent with the results of studies done in Ethiopia, ${ }^{19,20}$ Nigeria, ${ }^{16}$ and Vietnam. ${ }^{22}$ That might be because respondents who had good knowledge about malaria prevention and control mechanisms developed a favorable attitude to the utilization of the new interventions.

In this study, rich households were more likely to be willing to purchase malaria vaccine compared to poor families. This result was in line with those of studies conducted in Ethiopia, ${ }^{19,20,27}$ Nigeria, $^{18}$ Thailand, ${ }^{26}$ Vietnam, ${ }^{22}$ and Burkina Faso. ${ }^{17}$ The possible justification might be that rich households tried to meet their preferences, increased the acquisition of healthcare services for their families and allocated additional resources for family health.

\section{Limitation}

The new vaccine was not started in Ethiopia at the time of this study. Therefore, the findings might not reflect the true demand for the service. There could be response bias as caregivers might intentionally underestimate their willingness and ability to pay in order to get the service cheap. Finally, the findings of this study could have been stronger if the study was conducted among household heads who are usually responsible for household income and expenses.

\section{Conclusion}

WTP for childhood malaria vaccine among caregivers in the study area was good. A significant increase was observed in the willingness to purchase the vaccine below the profile price or vice versa. The finding also gave evidence on the ability and the willingness of respondents to pay for the vaccine. It is of great value to policy- makers to understand the price sensitivity before setting the price of the vaccine. Policy-makers should look for a price that would maximise demand and cover the cost of the vaccine. Moreover, educating caregivers and designing a reimbursement mechanism for the costs incurred by the poorest households might enhance their WTP for malaria vaccine.

\section{Abbreviations}

AOR, Adjusted Odds Ratio; CBHI, Community Based Health Insurance; CI, Confidence Interval; COR, Crude Odds Ratio; HPV, Human Papilloma Virus; MV, Malaria Vaccine: SPSS, Statistical Package for Social Sciences; UN, United Nations; WHO, World Health Organization; WTP, Willingness to Pay.

\section{Data Sharing Statement}

Data will be available upon reasonable request from the corresponding author. However, the data cannot be made public to maintain the caregiver's privacy and legal reasons as it contains private health information along with identifiers.

\section{Acknowledgments}

The authors would like to thank the participants for volunteering participation in the study and the University of Gondar for funding.

\section{Author Contributions}

All authors made a significant contribution to the work reported, whether that is in the conception, study design, execution, acquisition of data, analysis and interpretation, or in all these areas; took part in drafting, revising or critically reviewing the article; gave final approval of the version to be published; have agreed on the journal to which the article has been submitted; and agree to be accountable for all aspects of the work.

\section{Disclosure}

The authors declared that they have no competing interests.

\section{References}

1. Abebe Alemu H-PF, Getnet G, Kassu A, Getie S, Noedl H. Comparison of Giemsa microscopy with nested PCR for the diagnosis of malaria in North Gondar, north-west Ethiopia. Malar J. 2014;174 (174.

2. Jeremy Barofsky CC, Anekwe T, Farzadfar F. The Economic Effects of Malaria Eradication: Evidence from an Intervention in Uganda. 2011. 
3. World Health Organization. First malaria vaccine in Africa: a potential new tool for child health and improved malaria control; 2018. Available from: https:/www.who.int/malaria/publications/atoz/ first-malaria-vaccine/en/. Accessed March 2, 2021.

4. World Health Organisation. World Malaria Report. 2017.

5. Ethiopian Federal Ministry of Health. Malaria Prevention Control Program. 2009.

6. World health Organisation. $Q \& A$ on the Malaria Vaccine Implementation Programme (MVIP). 2018.

7. Aaby P, Rodrigues A, Kofoed P-E, Benn CS. RTS, S/AS01 malaria vaccine and child mortality. Lancet. 2015;386(10005):1735-1736. doi:10.1016/S0140-6736(15)00693-5

8. Alelign A, Dejene T. Current status of malaria in Ethiopia: evaluation of the burden, factors for transmission and prevention methods. Acta Parasitologica Globalis. 2016;7(1):01-06.

9. Tarekegn SolomonID EL, Deressa W. Low use of long-lasting insecticidal nets for malaria prevention in south-central Ethiopia: a community-based cohort study. PLoS One. 2019.

10. Galactionova KBM, Lauer J, Tediosi F, Tediosi F. Costing RTS,S introduction in Burkina Faso, Ghana, Kenya, Senegal, Tanzania, and Uganda: a generalizable approach drawing on publicly available data. Vaccine. 2015;33(48):6710-6718. doi:10.1016/j.vaccine.2015.10.079

11. Vandoolaeghe P. Le vaccin antipaludique RTS,S/AS01 chez les enfants âgés de 5 à 17 mois au moment de la première vaccination [The RTS,S/AS01 malaria vaccine in children aged 5-17 months at first vaccination] 1. 19 Jun. 2018. Pan Afr Med J. 2018;30(142).

12. World Health Organization. UNICEF: WHO/UNICEF; 2015. Available from: http://apps.who.int/immunization_monitoring/global summary/countries?countrycriteria $\% 5$ Bcountry $\% 5 \mathrm{D} \% 5 \mathrm{~B} \% 5 \mathrm{D}=$ GHA\&commit=OK. Accessed July 25, 2016.

13. Binnendijk HH. Designing Community-Based Health Insurance Among Rural Poor in India: A Novel Time-And Cost-Effective Method for Data Sourcing. 2014.

14. Agency EHI. Evaluation of Community-based Health Insurance Pilot Schemes in Ethiopia. Ethiopia: Ethiopian Health Insurance Agency Addis Ababa; 2015.

15. Cripps G, Edmond J, Killian R. Guide to Designing and Managing Community-Based Health Financing Schemes in East and Southern Africa. Abt Associations, Partnerships for Health Reform; 2000.

16. Beliretu I Abdulkadir IOA, Kamau AW, Gachigi JK, Habluetzel A, Mbogo CM. Willingness to accept malaria vaccine among caregivers of under-5 children in Ibadan North Local Government Area, Nigeria. MalariaWorld J. 2015;6(2).
17. Rainersauerborn A, Hengjindong JP, Dong H, Przyborski JM, Lanzer M. Willingness to pay for hypothetical malaria vaccines in rural Burkina Faso. Scand J Public Health. 2005;33(2):146-150. doi:10.1080/14034940510005743

18. Waka Anthony Udezi MCOU, Ihimekpen OO. Willingness to pay for three hypothetical malaria vaccines in Nigeria. Clin Ther. 2010;8:32.

19. Maureen L, Croppera B, Hailec M, Lampiettib J, Poulosd C, Whittingtone D. The demand for a malaria vaccine: evidence from Ethiopia. J Dev Econ. 2004;75(1):303-318. doi:10.1016/j.jdeveco. 2003.02.006

20. Yismaw A. Health professionals' willingness to pay and associated factors for human papilloma virus vaccination to prevent cervical cancer at college of medicine and health sciences University of Gondar, Northwest Ethiopia. BMC Res Notes. 2019;12(58):40 85-4087.

21. KJaAN A. Determinants of demand for health care in Bangladesh: an econometric analysis. In: 3rd Asia-Pacific Business Research Conference; 2013.

22. Canh DG, Whittington D, Thoa LT, et al. Household Demand for Typhoid Fever Vaccines in Hue, Vietnam. 2006.

23. Chukwuocha UM, Okorie PC, Iwuoha GN, Ibe SN, Dozie IN, Nwoke BE. Awareness, perceptions and intent to comply with the prospective malaria vaccine in parts of South Eastern Nigeria. Malar J. 2018;17(1):187. doi:10.1186/s12936-018-2335-0

24. Ojakaa DI, Jarvis JD, Matilu MI, Thiam S. Acceptance of a malaria vaccine by caregivers of sick children in Kenya. Malar J. 2014;13 (1):172. doi:10.1186/1475-2875-13-172

25. Gebresilassie FE, Mariam DH. Factors influencing people's willingness-to-buy insecticide-treated bednets in Arbaminch Zuria district, southern Ethiopia. J Health Popul Nutr. 2011;29(29):200-206. doi:10.3329/jhpn.v29i3.7867

26. Dale Whittington CS, Poulos C, Ainsworth M, Prabhu V, Tangcharoensathien V. Household demand for preventive HIV/ AIDS vaccines in Thailand: do husbands' and wives' preferences differ? Value Health. 2008;11.

27. Kumlachew AAW, Shimels H, Ayalew A. Association between socioeconomic status and willingness to pay for medical care among government school teachers in Addis Ababa. Sci J Public Health. 2015;3(5):677-685. doi:10.11648/j.sjph.20150305.23
ClinicoEconomics and Outcomes Research

\section{Publish your work in this journal}

ClinicoEconomics and Outcomes Research is an international, peerreviewed open-access journal focusing on Health Technology Assessment, Pharmacoeconomics and Outcomes Research in the areas of diagnosis, medical devices, and clinical, surgical and pharmacological intervention. The economic impact of health policy and health systems organization also constitute important areas of coverage. The manuscript management system is completely online and includes a very quick and fair peer-review system, which is all easy to use. Visit http://www.dovepress.com/testimonials.php to read real quotes from published authors.

Submit your manuscript here: https://www.dovepress.com/clinicoeconomics-and-outcomes-research-journal 